\title{
Frequency-Domain Ship Motion Code with Python Programming Language
}

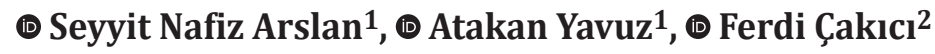 \\ ${ }^{1}$ Military Factory and Shipyard Management Inc., Ankara, Turkey \\ ${ }^{2}$ Ylldız Technical University, Department of Naval Architecture and Marine Engineering, İstanbul, Turkey
}

\begin{abstract}
In this study, a frequency-domain seakeeping code is established. A container ship was selected as an example to demonstrate the outputs of the code in different headings, ranging from the beam to head waves. Tasai's method is used to obtain two-dimensional hydrodynamic added mass and damping coefficients. For different loading conditions, the damping values for the roll motion can be obtained using Ikeda's method. Froude Krylov and Diffraction terms for pitch and heave motions are computed using the head seas approximation. A user-friendly interface is designed for presenting frequency-domain analyses. Vertical motions, vertical accelerations, and some derived motion characteristics, such as deck wetness, slamming, and absolute vertical accelerations are plotted as transfer functions. The entire procedure is implemented using Python code.
\end{abstract}

Keywords

Seakeeping code, Tasai's method, Derived motions, Ikeda's method

\section{Introduction}

In this study, the vertical motions of a ship are calculated in the frequency domain using the Python programming language. The vertical motions of the ship have three degrees of freedom. These motions are called heave, roll, and pitch. Evaluation and optimization of these motions, which are the subject of seakeeping, are extremely crucial for the safety of the passengers and crew. The enhancement of the ship's vertical motions enhances the habitability, operability, mobility, and survivability of the ship.

Ursell's [1] groundbreaking work set the path for the development of ship motion theories. The author demonstrated regular oscillations of a heaving circular cylinder in water and subsequently obtained hydrodynamic characteristics, such as added mass and damping. The velocity potential and conjugate stream function of heave motion in two dimensions were determined using multipole expansion theory [1,2]. Ursell's [1] study was improved by Tasai [3], who used the Lewis conformal mapping method to transform the hydrodynamic coefficients of a circular cylinder into shiplike sections. However, these calculations were insufficient for ships with sharp forms. Frank focused on this problem, and the author developed a pulsating source method to solve it. In this method, the Green function approach was used to represent the velocity potential of the unknown source density [4]. The researchers also published papers revealing the hydrodynamic coefficients of threedimensional ship geometries. Korvin-Kroukovsky and Jacobs [5] presented the first strip theory approach (the ordinary strip theory) using multipole expansion and mapping techniques. Salvesen et al. [6] developed the "New Strip Theory" method using the Close-Fit method. Another significant development in ship motion was the transition from regular waves to irregular waves in ship motion solutions using a novel method presented by St Denis and Pierson [7]. These two researchers presented a novel statistical energy distribution method that enabled the linearization of irregular waves. This theory (also known as the random process theory) is based on

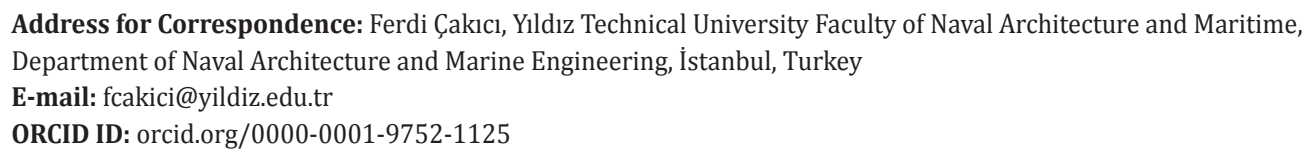

To cite this article: S. Y. Arslan, A. Yavuz and F. Çakıcı. "Frequency-Domain Ship Motion Code with Python Programming Language." Journal of ETA Maritime Science, vol. 9(4), pp. 283-291, 2021.

${ }^{\circ}$ Copyright 2021 by the Journal of ETA Maritime Science published by UCTEA Chamber of Marine Engineers 
two main assumptions: the sea surface has a normal distribution and the wave amplitude and ship motions are linearly related.

Owing to its speed and reliability, "The Strip Theory" is used in many studies in the seakeeping field, such as comfort onboard analysis and optimization works. The purpose of this study is to develop an in-house seakeeping code. Herein, hydrodynamic coefficients of sectional ship contours are calculated using conformal mapping developed by Lewis [2], and the multipole expansion theory developed by Ursell and Tasai. The novel strip theory by Salvesen et al. [6] was used to calculate the global hydrodynamic coefficients. Roll motion dynamics in the code were included using Ikeda's [8] method.

\section{Definition of Ship Model and Coordinate System}

Before the theories and methods for this study are explained, the description of the adopted container ship is provided. The body lines and the coordinate system of the ship are given in Figures 1a and 1b, respectively.

This sample container ship taken from the MAXSURF naval architecture program shows the seakeeping code outputs [9]. The main dimensions and several properties of the ship are listed in Table 1. The main reason for selecting this ship is that it features sections (fine sections) that are suitable for Lewis conformal mapping.

To compare the irregular wave results, the proposed limitations are determined in Table 2 [10].

\section{Lewis Conformal Mapping}

As previously stated, the sectional contours of the ship are obtained using Lewis conformal mapping [2]. Lewis conformal mapping is often simple to use. However, this method does not always result in a successful transformation of the ship's cross-section. The proper Lewis forms must be determined before performing the Lewis conformal
Table 1. The main dimension and loading conditions of the container ship

\begin{tabular}{|c|c|c|}
\hline Main Dimensions & Magnitudes & Units \\
\hline $\mathrm{L}_{\text {wL }}$ (Length of waterline) & 111,187 & Meter \\
\hline B (Breadth) & 19.5 & Meter \\
\hline $\mathrm{T}$ (Draft) & 7,239 & Meter \\
\hline CB (Block coefficient) & 0.693 & - \\
\hline$\rho$ (Density of sea) & 1.025 & $\mathrm{t} / \mathrm{m}^{3}$ \\
\hline$\Delta$ (Displaced mass of ship) & 11156 & Ton \\
\hline LCB (longitudinal center of buoyancy) & 54,030 & Meter \\
\hline LCG (longitudinal center of gravity) & 54,030 & Meter \\
\hline VCB (vertical center of buoyancy) & 3,783 & Meter \\
\hline VCG (vertical center of gravity) & 6 & Meter \\
\hline The gyration radius of pitch motion & 29,053 & Meter \\
\hline The gyration radius of roll motion & 7.8 & Meter \\
\hline
\end{tabular}

Table 2. The performance limitations for the given ship

\begin{tabular}{|c|c|c|}
\hline Motion & Limit & Location \\
\hline Deck wetness index & $30 /$ hour & Bow \\
\hline Slamming index & $20 /$ hour & Keel \\
\hline Propeller emergence index & $90 /$ hour & $1 / 4$ propeller diameter \\
\hline Vertical acceleration & 0.2 g (RMS) & Task location \\
\hline \multicolumn{3}{|c|}{ RMS: Root mean square } \\
\hline
\end{tabular}

mapping. The general transformation formula is given below (Equation 1).

$Z=M_{s} \sum_{n=0}^{N}\left(a_{2 n-1} \varsigma^{-(2 n-1)}\right)$

where $\mathrm{M}_{\mathrm{s}}$ is the Scale factor, $\mathrm{a}_{2 \mathrm{n}-1}$ represents the conformal mapping coefficients, and $\mathrm{N}$ is the number of parameters

The plane of the ship's cross-section (Equation 2) and the plane of the unit circle (Equation 3) are given below. The transverse and vertical coordinates of the ship's crosssection are represented by $\mathrm{X}$ and $\mathrm{Y}$, respectively.
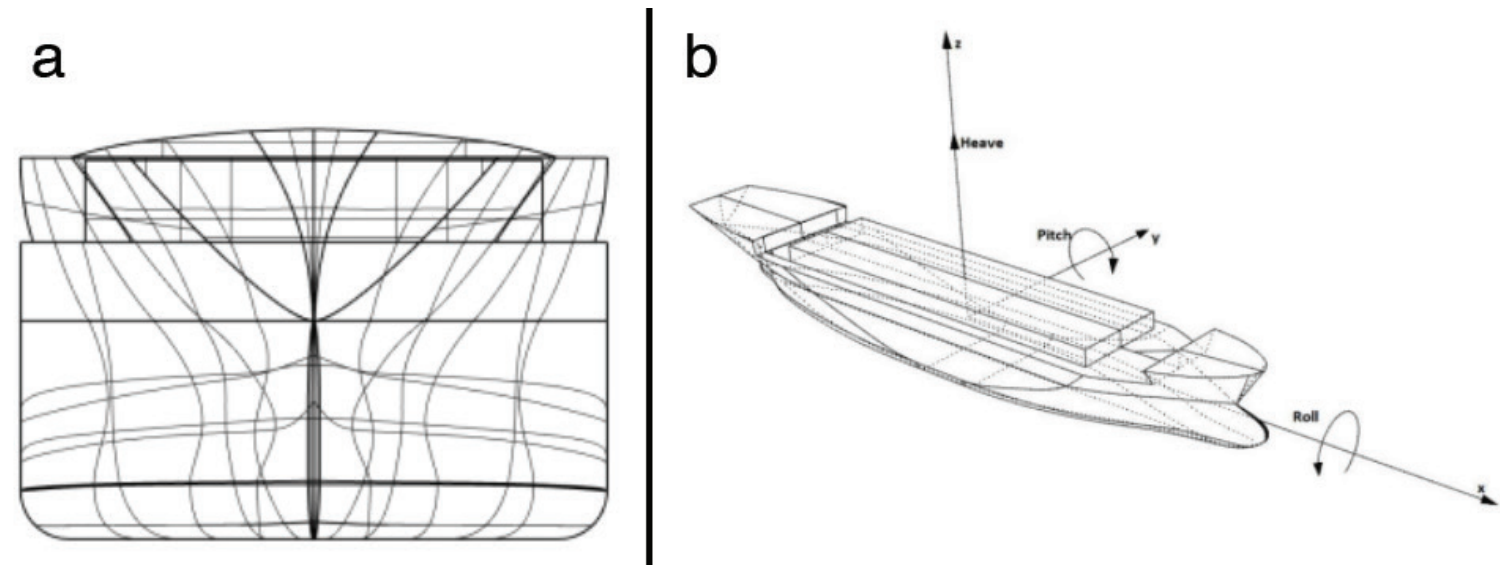

Figure 1. The body lines (a) and the coordinate system of the container ship (b) 


$$
\begin{aligned}
& Z=X+i Y \\
& \varsigma=i e^{\alpha} e^{-i \theta}
\end{aligned}
$$

The next step is to perform the Lewis conformal mapping with $\mathrm{N}=2$. The Lewis transformation formula is given below (Equation 4).

$$
Z=M_{s}\left(a_{-1} \varsigma+a_{1} \varsigma^{-1}+a_{3} \varsigma^{-3}\right)
$$

The contour coordinates of this Lewis form can be obtained using $\alpha=0$, and the transverse and vertical coordinates of the ship's cross-section contour are given below (Equations 5 and 6) $\left(\mathrm{a}_{-1}=+1\right)$.

$X_{0}=M_{s}\left(\left(1+a_{1}\right) \sin \theta-a_{3} \sin 3 \theta\right)$

$Y_{0}=M_{s}\left(\left(1-a_{1}\right) \cos \theta+a_{3} \cos 3 \theta\right)$

The scale factor is given below (Equation 7). $\mathrm{B}_{\mathrm{s}}$ is the sectional breadth along the ship.

$$
M_{s}=\frac{B_{s} / 2}{1+a_{1}+a_{3}}
$$

In Equations 8 and 9, the half breadth to draft ratio and the sectional area coefficient are given, respectively.

$$
\begin{aligned}
& H_{0}=\frac{B_{s} / 2}{T_{s}}=\frac{1+a_{1}+a_{3}}{1-a_{1}+a_{3}} \\
& \sigma_{s}=\frac{A_{s}}{B_{s} T_{s}}=\frac{\pi}{4} \cdot \frac{1-a_{1}{ }^{2}-3 a_{3}^{2}}{\left(1+a_{3}\right)^{2}-a_{1}^{2}},
\end{aligned}
$$

where $\mathrm{A}_{\mathrm{s}}$ and $\mathrm{T}_{\mathrm{s}}$ represent the cross-sectional areas and drafts along the ship, respectively. With these equations (Equations 8 and 9), Equation 10 can be obtained.

$$
c_{1} a_{3}^{2}+c_{2} a_{3}+c_{3}=0
$$

The solutions of Equation 10 (Equations 11-13) are given below.

$$
\begin{aligned}
& c_{1}=3+\frac{4 \sigma_{s}}{\pi}+\left(1-\frac{4 \sigma_{s}}{\pi}\right) \cdot\left(\frac{H_{0}-1}{H_{0}+1}\right)^{2} \\
& c_{2}=2 c_{1}-6 \\
& c_{3}=c_{1}-4
\end{aligned}
$$

With these solutions, the Lewis conformal mapping coefficients can be determined (Equations 14 and 15) [11].

$$
\begin{aligned}
& a_{3}=\frac{-c_{1}+3+\sqrt{9-2 c_{1}}}{c_{1}} \\
& a_{1}=\frac{H_{0}-1}{H_{0}+1} \cdot\left(a_{3}+1\right)
\end{aligned}
$$

\section{Tasai's Theory}

Calculating the three-dimensional hydrodynamic coefficients of the ship is often complicated. Therefore, using the strip theory method, these three-dimensional coefficients can be acquired based on two-dimensional hydrodynamic coefficients of the ship. Accordingly, the sectional added mass and damping coefficients for heave motion were determined by Tasai [3] in 1959. In this section, two-dimensional hydrodynamic added mass and damping coefficients for heave motion are obtained using Tasai's method. The approximations for this method are that the forward speed of the ship is zero, the ship is in deep water, and an infinitely long cylinder is in the free surface of a fluid. To calculate the sectional added mass and damping coefficients for heave motion, $A_{0}, B_{0}, M_{0}$, and $N_{0}$ coefficients must be determined, and the values required to compute these coefficients are given below (Equations 16-20).

$$
\begin{aligned}
& \phi_{B_{c}}=\pi e^{-v Y} \cos (v X) \\
& \phi_{B_{s}}=\pi e^{-v Y} \sin (v X)+\int_{0}^{\infty} \frac{v \sin (k Y)-k \cos (k Y)}{k^{2}+v^{2}} e^{-k|X|} d k \\
& \psi_{B_{c}}=\pi e^{-v Y} \sin (v X) \\
& \psi_{B_{s}}=-\pi e^{-v Y} \cos (v X)+\int_{0}^{\infty} \frac{v \cos (k Y)+k \sin (k Y)}{k^{2}+v^{2}} e^{-k|X|} d k \\
& \psi_{A 0_{2 n}}(\theta)=\sin (2 m \theta)-\frac{\xi_{b}}{\lambda_{a}} \sum_{n=0}^{N}\left\{(-1)^{n} \frac{2 n-1}{2 m+2 n-1} a_{2 n-1} \sin ((2 m+2 n-1) \theta)\right\},
\end{aligned}
$$

where: $\frac{\xi_{b}}{\lambda_{a}}=\frac{\omega_{e}^{2}}{g} M_{s}$ or $\xi_{b}=\frac{\omega_{e}^{2} B_{s}}{2 g}$ and $\lambda_{a}=\sum_{n=0}^{N} a_{2 n-1}$ and $v=\frac{\omega_{e}^{2}}{g}$,

where $\omega_{\mathrm{e}}$ is the encounter frequency and $\mathrm{g}$ is the gravitational acceleration [11]. The integrations in Equation 17 and Equation 19 can be solved using Porter's [12] method. The convergence is relatively rapid using this method [11]. For $\mathrm{P}_{2 \mathrm{~m}}$ and $\mathrm{Q}_{2 \mathrm{~m}}$, two sets of $\mathrm{M}$ equations are given below (in this study, M is taken to be 6) (Equations 21, 22).

$$
\begin{aligned}
& \sum_{m=1}^{M}\left\{P_{2 m} \int_{0}^{\pi / 2} f_{2 m}(\theta) f_{2 n}(\theta) d \theta\right\}=\int_{0}^{\pi / 2}\left(\psi_{B 0_{c}}(\theta)-h(\theta) \psi_{B 0_{c}}\left(\frac{\pi}{2}\right)\right) f_{2 n}(\theta) d \theta ; n=1, \ldots \ldots, M \\
& \sum_{m=1}^{M}\left\{Q_{2 m}^{\pi / 2} \int_{0}^{\pi m}(\theta) f_{2 n}(\theta) d \theta\right\}=\int_{0}^{\pi / 2}\left(\psi_{B 0_{s}}(\theta)-h(\theta) \psi_{B 0_{0}}\left(\frac{\pi}{2}\right)\right) f_{2 n}(\theta) d \theta ; n=1, \ldots \ldots, M
\end{aligned}
$$

In which:

$$
f_{2 m}(\theta)=-\psi_{A 0_{2 n}}(\theta)+h(\theta) \psi_{A 0_{2 n}}\left(\frac{\pi}{2}\right) \text { and } h(\theta)=\frac{2 X_{0}}{B_{s}}=-\frac{1}{\lambda_{a}} \sum_{n=0}^{N}\left\{(-1)^{n} a_{2 n-1} \sin ((2 n-1) \theta)\right\}
$$

Now, $A_{0}, B_{0}, M_{0}$, and $N_{0}$ coefficients can be expressed as follows (Equations 23-26):

$A_{0}=\psi_{B 0_{c}}\left(\frac{\pi}{2}\right)+\sum_{m=1}^{\infty}\left\{P_{2 m} \psi_{A 0_{2 m}}\left(\frac{\pi}{2}\right)\right\}$

$B_{0}=\psi_{B 0_{s}}\left(\frac{\pi}{2}\right)+\sum_{m=1}^{\infty}\left\{Q_{2 m} \psi_{A 0_{2 m}}\left(\frac{\pi}{2}\right)\right\}$ 


$$
\begin{aligned}
M_{0}= & -\frac{1}{\lambda_{a}} \int_{0}^{\pi / 2} \phi_{B 0_{s}}(\theta) \sum_{n=0}^{N}\left\{(-1)^{n}(2 n-1) a_{2 n-1} \cos ((2 n-1) \theta)\right\} d \theta \\
& -\frac{1}{\lambda_{a}} \sum_{m=1}^{M}\left\{(-1)^{m} Q_{2 m} \sum_{n=0}^{N}\left\{\frac{(2 n-1)^{2}}{(2 m)^{2}-(2 n-1)^{2}} a_{2 n-1}\right\}\right\} \\
& +\frac{\pi \xi_{b}}{4 \lambda_{a}^{2}}\left(Q_{21}+\sum_{m=1}^{N}\left\{(-1)^{m} Q_{2 m} \sum_{n=0}^{N-m}\left\{(2 n-1) a_{2 n-1} a_{2 m+2 n-1}\right\}\right\}\right), \quad \text { for }: M \geq N \\
N_{0}= & -\frac{1}{\lambda_{a}} \int_{0}^{\pi / 2} \phi_{B 0_{c}}(\theta) \sum_{n=0}^{N}\left\{(-1)^{n}(2 n-1) a_{2 n-1} \cos ((2 n-1) \theta)\right\} d \theta \\
& -\frac{1}{\lambda_{a}} \sum_{m=1}^{M}\left\{(-1)^{m} P_{2 m} \sum_{n=0}^{N}\left\{\frac{(2 n-1)^{2}}{(2 m)^{2}-(2 n-1)^{2}} a_{2 n-1}\right\}\right\} \\
& +\frac{\pi \xi_{b}}{4 \lambda_{a}^{2}}\left(P_{21}+\sum_{m=1}^{N}\left\{(-1)^{m} P_{2 m} \sum_{n=0}^{N-m}\left\{(2 n-1) a_{2 n-1} a_{2 m+2 n-1}\right\}\right\}\right), \quad \text { for }: M \geq N
\end{aligned}
$$

Finally, as shown below, the sectional potential added mass and damping coefficients can be determined (Equations 27, 28).

$a_{z}=\frac{\rho B_{s}^{2}}{2} \cdot \frac{M_{0} B_{0}+N_{0} A_{0}}{A_{0}^{2}+B_{0}^{2}}$

$b_{z}=\frac{\rho B_{s}^{2}}{2} \cdot \frac{M_{0} A_{0}-N_{0} B_{0}}{A_{0}^{2}+B_{0}^{2}} \omega_{e}$

\section{Salvesen et al. [6] Strip Theory}

Strip theory is a useful theory that enables us to calculate the global hydrodynamic coefficients of a three-dimensional ship using two-dimensional hydrodynamic coefficients of the ship sections. Two-dimensional coefficients calculation is preferable since it is much easier than directly determining coefficients of a three-dimensional ship. There are certain restrictions when using the strip theory. These restrictions can be summarized as follows: the flow must be potential, and the body of the ship must be slender. As previously stated, the focus of this study is on frequency-domain ship vertical motions. Therefore, the vertical motions of the ship are heave, roll, and pitch motions, which are all within the scope of seakeeping. It is assumed that heave and pitch motions are coupled motions, while roll motion is an uncoupled motion. Heave, pitch, and roll motions equations are listed below, respectively (Equations 29, 30, and 31).

$$
\begin{aligned}
& \left(M+A_{33}\right) \ddot{\eta}_{3}+B_{33} \dot{\eta}_{3}+C_{33} \eta_{3}+A_{35} \ddot{\eta}_{5}+B_{35} \dot{\eta}_{5}+C_{35} \eta_{5}=F_{3} e^{i \omega_{e} t} \\
& \left(I_{5}+A_{55}\right) \ddot{\eta}_{5}+B_{55} \dot{\eta}_{5}+C_{55} \eta_{5}+A_{53} \ddot{\eta}_{3}+B_{53} \dot{\eta}_{3}+C_{53} \eta_{3}=F_{5} e^{i \omega_{e} t} \\
& \left(I_{4}+A_{44}\right) \ddot{\eta}_{4}+B_{44} \dot{\eta}_{4}+C_{44} \eta_{4}=F_{4} e^{i \omega_{e} t}
\end{aligned}
$$

In which:

j, k: Subscripts (j, k=3, 4, 5 refer to heave, roll, and pitch, respectively)

$\mathrm{A}_{\mathrm{jk}}$ : Added mass coefficients

$\mathrm{B}_{\mathrm{j} \mathrm{k}}$ : Damping coefficients

$\mathrm{C}_{\mathrm{jk}}$ : Hydrostatic restoring coefficients

$\mathrm{F}_{\mathrm{j}}$ : Exciting forces ad moments
$\mathrm{I}_{\mathrm{j}}$ : Moment of inertia

M: Mass of the ship

$\eta_{j}$ : Displacements

$\dot{\eta}_{j}:$ Velocities

$\ddot{\eta}_{j}$ : Accelerations

The global hydrodynamic coefficients of the heave, roll, and pitch motion equations are provided below (Equations 3246) [6].

$$
\begin{aligned}
& A_{33}=\int_{-L / 2}^{L / 2} a_{z} d x-\frac{V}{\omega_{e}^{2}} b_{z}^{A} \\
& B_{33}=\int_{-L / 2}^{L / 2} b_{z} d x+V a_{z}^{A}
\end{aligned}
$$

$A_{35}=-\int_{-L / 2}^{L / 2} x a_{z} d x-\frac{V}{\omega_{e}{ }^{2}} B_{33}^{0}+\frac{V}{\omega_{e}{ }^{2}} x_{A} b_{z}^{A}-\frac{V^{2}}{\omega_{e}{ }^{2}} a_{z}^{A}$

$B_{35}=-\int_{-L / 2}^{L / 2} x b_{z} d x+V A_{33}^{0}-V x_{A} a_{z}^{A}-\frac{V^{2}}{\omega_{e}^{2}} b_{z}^{A}$

$A_{53}=-\int_{-L / 2}^{L / 2} x a_{z} d x+\frac{V}{\omega_{e}^{2}} B_{33}^{0}+\frac{V}{\omega_{e}^{2}} x_{A} b_{z}^{A}$

$B_{53}=-\int_{-L / 2}^{L / 2} x b_{z} d x-V A_{33}^{0}-V x_{A} a_{z}^{A}$

$A_{55}=\int_{-L / 2}^{L / 2} x^{2} a_{z} d x+\frac{V^{2}}{\omega_{e}{ }^{2}} A_{33}^{0}-\frac{V}{\omega_{e}{ }^{2}} x_{A}^{2} b_{z}^{A}+\frac{V^{2}}{\omega_{e}^{2}} x_{A} a_{z}^{A}$

$B_{55}=\int_{-L / 2}^{L / 2} x^{2} b_{z} d x+\frac{V^{2}}{\omega_{e}{ }^{2}} B_{33}^{0}+V x_{A}^{2} a_{z}^{A}+\frac{V^{2}}{\omega_{e}{ }^{2}} x_{A} b_{z}^{A}$

$C_{33}=\rho g \int_{-L / 2}^{L / 2} B_{s} d x=\rho g A_{W P}$

$C_{35}=C_{53}=-\rho g \int_{-L / 2}^{L / 2} x B_{s} d x$

$C_{55}=\rho g \int_{-L / 2}^{L / 2} x^{2} B_{s} d x$

$I_{5}=M \cdot k_{y y}^{2} ; 0.25 L_{W L} \leq k_{y y} \leq 0.30 L_{W L}$

$I_{4}=M \cdot k_{x x}^{2} ; 0.35 B \leq k_{x x} \leq 0.40 B$

$0.20 \cdot I_{4}<A_{44}<0.30 \cdot I_{4}$

$C_{44}=\rho \cdot g \cdot \nabla \cdot G M_{t}$

In which:

$\mathrm{V}$ denotes ship forward speed, $\mathrm{b}_{\mathrm{z}}{ }^{\mathrm{A}}$ denotes $\mathrm{b}_{\mathrm{z}}$ for aftermost section, $\mathrm{a}_{\mathrm{z}}{ }^{\mathrm{A}}$ denotes $\mathrm{a}_{\mathrm{z}}$ for aftermost section, $\mathrm{B}_{33}{ }^{0}$ denotes speed-independent part of $B_{33}, x_{A}$ denotes $x$-coordinate of aftermost cross-section, $A_{33}{ }^{0}$ denotes speed-independent part of $A_{33}, k_{y y}$ denotes pitch gyration radius, $\mathrm{k}_{\mathrm{xx}}$ denotes roll gyration radius, $\mathrm{GM}_{\mathrm{t}}$ denotes metacentric height, and $\nabla$ denotes displaced volume of the ship. 
As can be seen, there is no equation for $\mathrm{B}_{44}$ (roll damping coefficient) because the roll damping coefficient is obtained using Ikeda's [8] method. The right-hand side of the heave and pitch motion equations are solved using the head seas approximation. Heave, pitch, and roll exciting forces and moments are given, (Equations 47-49) [6]. It is worth noting that the head seas for heave force and pitch moment assumption used in the code may produce realistic results only for the $160^{\circ}$ to $180^{\circ}$ range [9].

$$
\begin{aligned}
F_{3}= & \zeta_{a} \int e^{i k x} e^{-k T_{s} \sigma_{s}}\left\{\rho g B_{s}-\omega_{0}\left(\omega_{e} a_{z}-i b_{z}\right)\right\} d x \\
& -\zeta_{a} \frac{V}{i \omega_{e}} e^{i k x_{A}} e^{-k T_{s} \sigma_{s}} \omega_{0}\left(\omega_{e} a_{z}^{A}-i b_{z}^{A}\right) \\
F_{5}= & -\zeta_{a} \int e^{i k x} e^{-k T_{s} \sigma_{s}}\left\{x\left[\rho g B_{s}-\omega_{0}\left(\omega_{e} a_{z}-i b_{z}\right)\right]\right. \\
& \left.-\frac{V}{i \omega_{e}} \omega_{0}\left(\omega_{e} a_{z}-i b_{z}\right)\right\} d x \\
& +\zeta_{a} \frac{V}{i \omega_{e}} e^{i k x_{A}} e^{-k T_{s} \sigma_{s}} \omega_{0} x_{A}\left(\omega_{e} a_{z}{ }^{A}-i b_{z}{ }^{A}\right) \\
F_{4}= & C_{44} \cdot \zeta_{a} \cdot k \cdot \sin \mu
\end{aligned}
$$

In which, $\mathrm{k}$ is the wavenumber, $\omega_{0}$ is the wave frequency, $\mu$ is the angle of encounter, $T_{s}$ is the sectional draught, $\sigma_{s}$ is the sectional area coefficient, and $\zeta_{a}$ is a small wave amplitude. After computing all global coefficients, exciting forces, and moments, Equations 29, 30, and 31 can be solved in the frequency domain using any linear equation solver method. Heave, roll, and pitch displacements are the results of the linear equation. It is worth noting that, unlike the heave displacement, roll and pitch are angularly displaced. Heave, roll, and pitch transfer functions (TF) are given below (Equations 50-52).

$$
\begin{aligned}
& \text { Heave TF }=\frac{\eta_{3}}{\zeta_{a}} \\
& \text { Roll TF }=\frac{\eta_{4}}{\zeta_{a} k}
\end{aligned}
$$

Pitch $T F=\frac{\eta_{5}}{\zeta_{a} k}$

\section{The Outputs of the Present Seakeeping Code}

The outputs of the seakeeping code are listed in this section. Before demonstrating the important results, some inputs used in the seakeeping code are explained in Table 3 (these inputs are the locations for propeller emergence, slamming, deck wetness, and absolute vertical acceleration are locations 1,2,3, and 4, respectively).

The longitudinal $\left(\mathrm{x}_{\mathrm{p}}\right)$ and the transverse $\left(\mathrm{y}_{\mathrm{p}}\right)$ distances are measured with the center of gravity. Here PSD, $\mathrm{T}_{\mathrm{L} 2}$, and $\mathrm{F}_{\mathrm{L} 3}$ represent propeller shaft depth, draft at location 2 , and
Table 3. Some seakeeping code inputs

\begin{tabular}{|c|c|c|}
\hline & Inputs & Units \\
\hline Angle of encounter & $90^{\circ}: 180^{\circ}: 15^{\circ}$ & Degree \\
\hline Fn (Froude number) & 0.2 & Dimensionless \\
\hline Sea state (SS) & 5 and 6 & - \\
\hline Sea & Black Sea & - \\
\hline Wave spectrum & Bretschneider wave spectrum & - \\
\hline Location 1 & $\mathrm{x}_{\mathrm{p}}:-51.678, \mathrm{y}_{\mathrm{p}}: 0, \mathrm{PSD}:-4.385$ & Meter \\
\hline Location 2 & $\mathrm{x}_{\mathrm{p}}: 45.444, \mathrm{y}_{\mathrm{p}}: 0, \mathrm{~T}_{\mathrm{L} 2}:-7.239$ & Meter \\
\hline Location 3 & $\mathrm{x}_{\mathrm{p}}: 45.444, \mathrm{y}_{\mathrm{p}}: 7.24, \mathrm{~F}_{\mathrm{L} 3}: 5.66$ & Meter \\
\hline Location 4 & $\mathrm{x}_{\mathrm{p}}:-45.527, \mathrm{y}_{\mathrm{p}}: 9.171$ & Meter \\
\hline
\end{tabular}

freeboard at location 3, respectively. It is worth noting that the upper side of the free surface and the head side of the ship are considered positive directions. In this study, sea states 5 and 6 (significant wave heights of the sea state 5 and 6 are 3.25 and 5 meters) were selected to show the irregular sea outputs.

The general steps and detailed inputs of the seakeeping code are given as flowcharts in Figures $2 \mathrm{a}$ and $2 \mathrm{~b}$, respectively.

In Figure $3 \mathrm{a}$, and Figure $3 \mathrm{~b}$ the sectional added mass coefficients for the $16^{\text {th }}$ and $25^{\text {th }}$ cross-sections of the container ship are compared with the MAXSURF outputs.

In Figure $4 \mathrm{a}$ and Figure $4 \mathrm{~b}$, the sectional damping coefficients for the $16^{\text {th }}$ and $25^{\text {th }}$ cross-sections of the container ship are compared with the MAXSURF outputs.

The results of the present seakeeping code (sectional added mass and damping coefficients) correlate well with the MAXSURF results, As shown in Figures 3 and 4. Figure 5a and Figure 5b compare MAXSURF commercial software outputs with certain global hydrodynamic added mass and damping coefficients, $\mathrm{A}_{35}$ and $\mathrm{B}_{53}$.

The results of the seakeeping code, in terms of global added mass and damping, are also highly reliable. These results can be seen in Figures $5 a$ and $5 b$.

The solution of Equation 29-31 for $F_{n}=0.2$ provided the regular sea results. Heave, roll, and pitch TFs are demonstrated in Figures $6 a, 6 b$, and $6 c$, respectively. It is worth noting that the input heading angles used ranged from $90^{\circ}$ to $180^{\circ}$ as seen from the figures below. However, the assumption of head seas is only valid for the $160^{\circ}$ to $180^{\circ}$ range. Therefore, the accuracy of the outputs outside of this range should be debated.

Following the demonstration of the general regular sea results, certain irregular wave outputs were also provided. These results are compared with the proposed limits in Table 2.

Figures $7 \mathrm{a}, 7 \mathrm{~b}$, and $7 \mathrm{c}$ demonstrate the number of propeller emergence, slamming, and deck wetness, respectively, for 


\section{a}

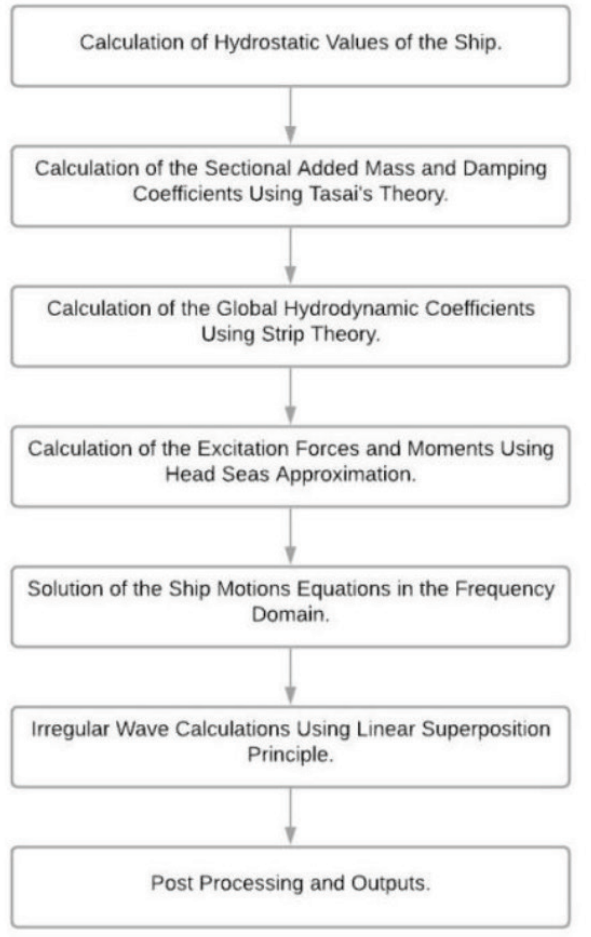

b

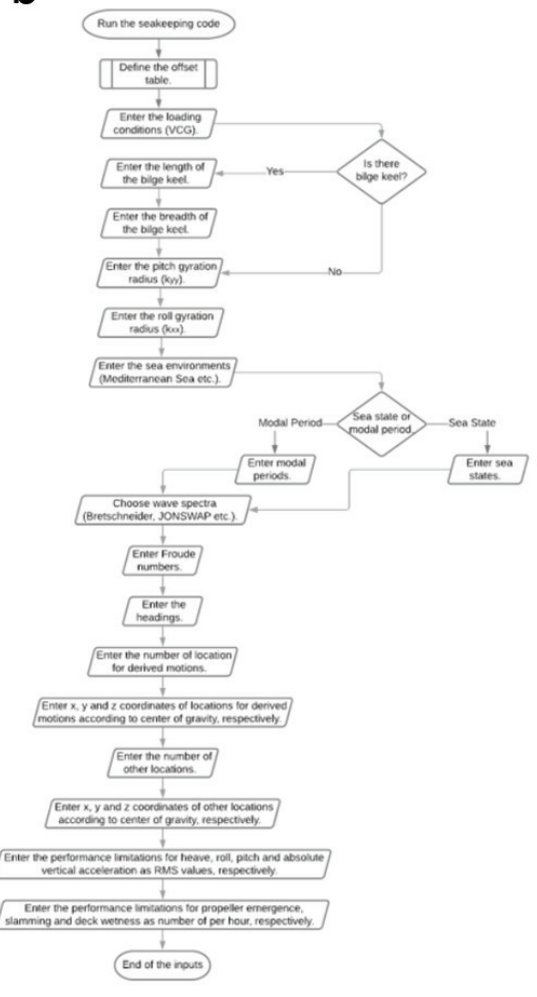

Figure 2. General steps (a) and detailed inputs of the seakeeping code (b)
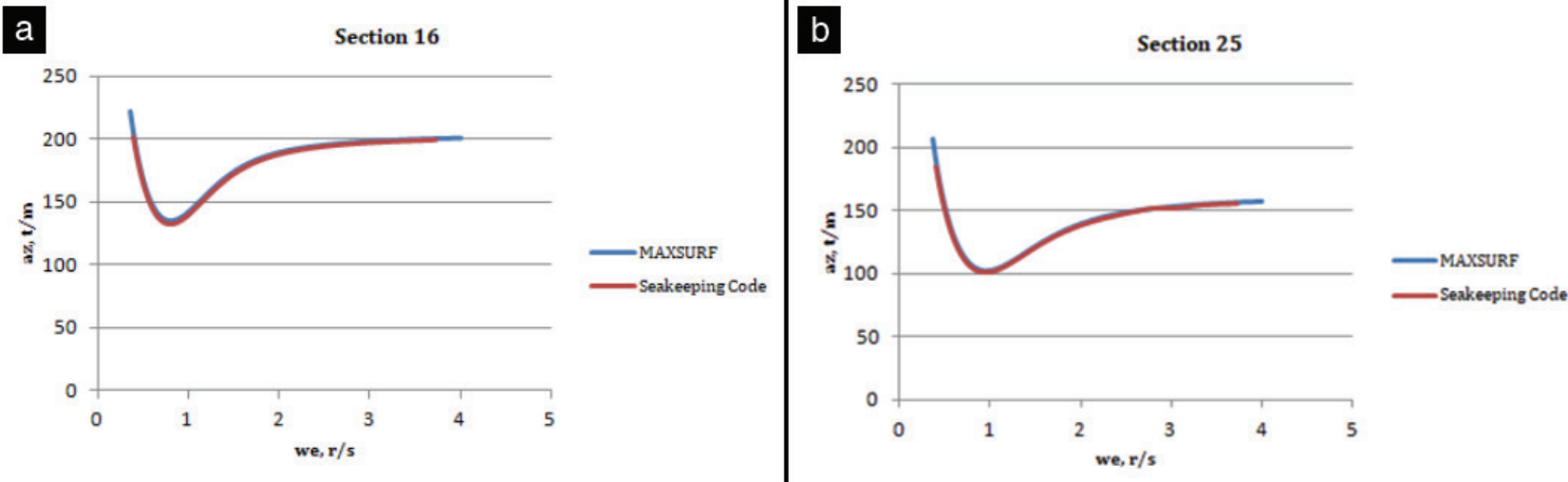

Figure 3. Sectional added mass coefficients comparison for sections 16 and 25

a

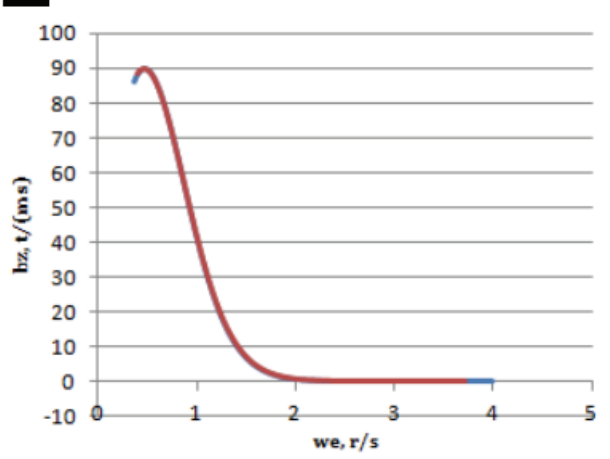

b

Section 25

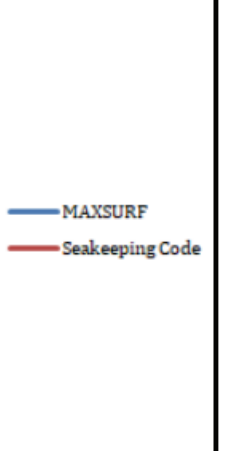

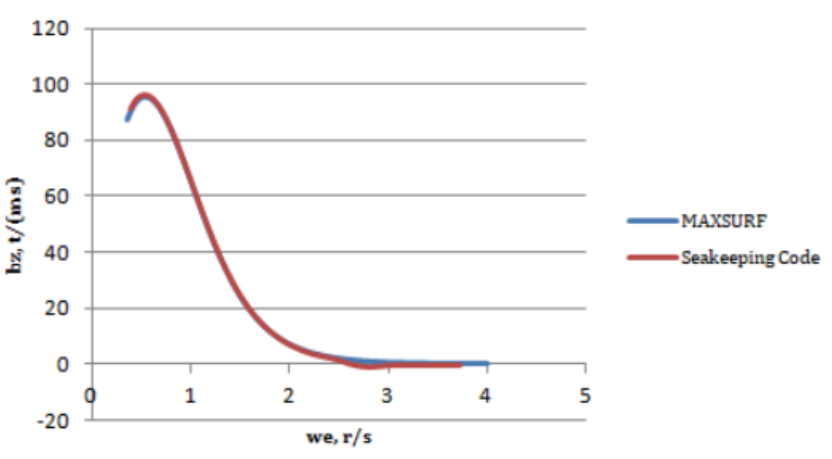

Figure 4. Sectional damping coefficients comparison for Sections 16 and 25 
a
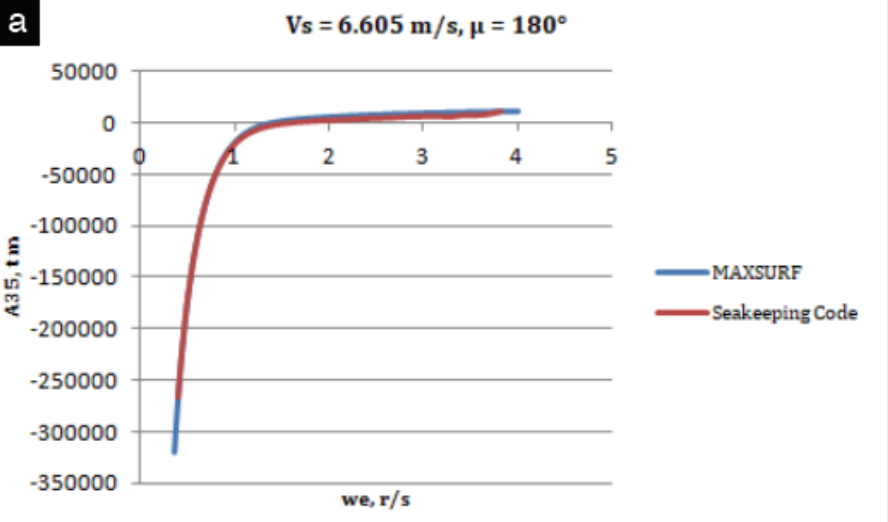

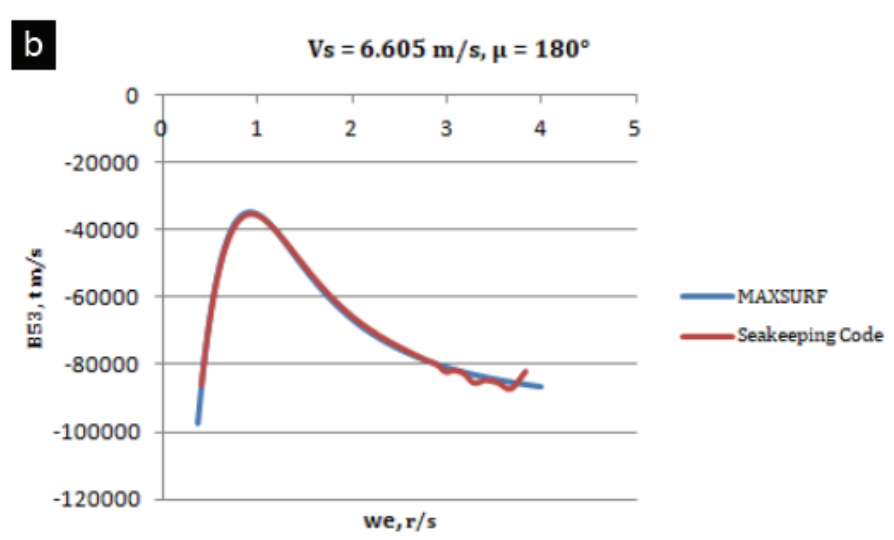

sea state 6. As previously stated, locations 1, 2, and 3 are for propeller emergence, slamming, and deck wetness, respectively. The absolute vertical acceleration values are given for the sea states 5 and 6 are shown in Figures $7 d$ and 7e, respectively. These vertical acceleration calculations are made for location 4 .

\section{Conclusion}

In this study, the frequency-domain ship motions are coded using Python programming language. The container ship is selected as an example to demonstrate the output of the present seakeeping code. This particular ship was selected because all its sections correlate with those determined by Lewis forms. All ship characteristics are determined by the trapezoid numerical integration method in the code with the use of the ship's offset data. Using Ursell and Tasai's multipole expansion theory and conformal mapping, the sectional added mass and damping coefficients are determined. Lewis conformal mapping $(\mathrm{N}=2)$ is performed to obtain the hydrodynamic coefficients. After obtaining the sectional hydrodynamic coefficients, the global hydrodynamic coefficients and the amplitudes of the exciting forces and moments are determined using the strip theory and head seas approximation. For roll motion damping values, Ikeda's method is utilized. After determining global coefficients, heave, pitch, and roll motion equations are solved, and the TFs of these displacements (heave, pitch, and roll) are properly obtained. The irregular wave calculations can be performed using the obtained TFs and the linear superposition principle. Several spectra and sea environments are defined in the code and based on these definitions, the vertical acceleration root mean square, number of propeller emergence per hour, number of slamming per hour, and number of deck wetness per hour are computed appropriately. The entire process is performed using Python code.

Figure 6. Heave, roll, and pitch $T F, F_{n}=0.2$ 

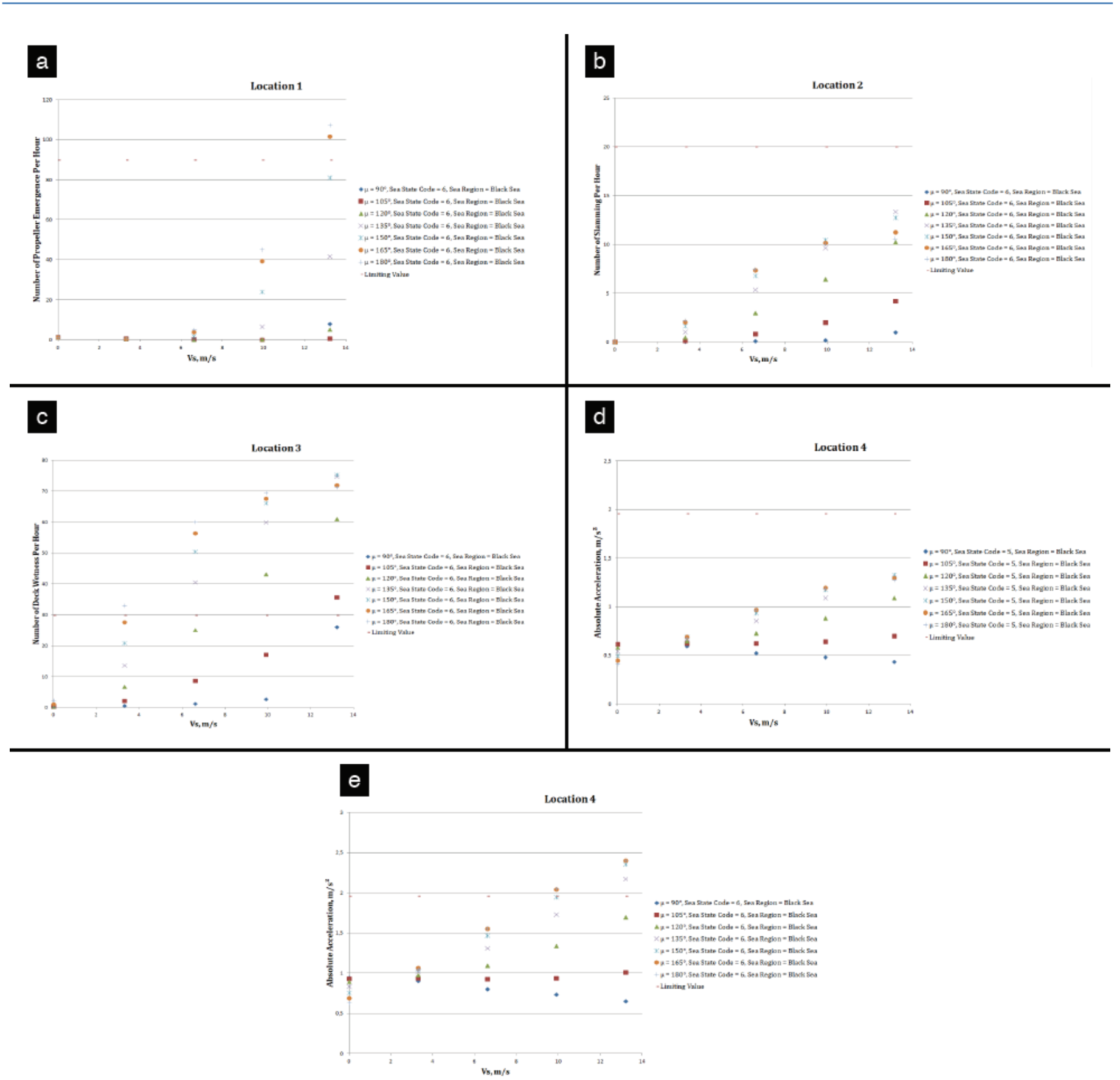

Figure 7. Certain irregular sea results

This study applied Lewis conformal mapping and head seas approximation for the conformal mapping method and sectional excitation terms, respectively. Close-fit conformal mapping and arbitrary wave heading will be considered in future studies.

\section{References}

[1] F. Ursell, "On the heaving motion of a circular cylinder on the surface of a fluid," The Quarterly Journal of Mechanics and Applied Mathematics, vol. 2, pp. 218-231, Jan 1949.
[2] F. M. Lewis, "The inertia of the water surrounding a vibrating ship," The Society of Naval Architects and Marine Engineers, vol. 27, pp. 1-20, Jun 1929.

[3] F. Tasai, "On the damping force and added mass of ships heaving and pitching," Tech. Rep. Research Institute for Applied Mechanics, Kyushu University, Japan, vol. 7, pp. 131152, 1969.

[4] W. Frank, "Oscillation of cylinders in or below the free surface of deep fluids," Tech. Rep. 2375, Naval Ship Research and Development Centre, Washington DC, USA, 1967. 
[5] B. V. Korvin-Kroukovsky, and W. R. Jacobs, "Pitching and heaving motions of a ship in regular waves," Transactions SNAME, vol. 65, pp. 590-632, Nov 1957.

[6] N. Salvesen, E. O. Tuck, and O. Faltinsen, "Ship motions and sea loads." The Society of Naval Architects and Marine Engineers, vol. 78, pp. 250-287, Dec 1970.

[7] M. St Denis, and W. Pierson, "On the motions of ships in confused seas," The Society of Naval Architects and Marine Engineers, vol. 61, pp. 280-354, 1953.

[8] Y. Ikeda, "A study on roll damping of ships," Ph. D. dissertation, Osaka Prefecture University, Japan, 1979.

[9] MAXSURF Connect Edition V21 Maxsurf User Manuel, Maxsurf Modeler, Maxsurf Motions, 2017.
[10] North Atlantic Treaty Organization (2000). Standardization Agreement (STANAG): Common Procedures for Seakeeping in the Ship Design Process. Brussels: North Atlantic Treaty Organization, Military Agency for Standardization.

[11] J. M. J. Journée, Theoretical manuel of seaway. Delft University of Technology Ship hydromechanics Laboratory, Netherlands, 2001.

[12] W. R. Porter, "Pressure distribution, added-mass and damping coefficients for cylinders oscillating in a free surface," Tech. Rep. 82, University of California, Institute of Engineering Research, Berkeley, California, USA, 1960. 